Article

\title{
Improving the Conductivity of Sulfonated Polyimides as Proton Exchange Membranes by Doping of a Protic Ionic Liquid
}

\section{Bor-Kuan Chen ${ }^{1, *}$, Jhong-Ming Wong ${ }^{1}$, Tzi-Yi Wu ${ }^{2}$, Lung-Chuan Chen ${ }^{1}$ and I-Chao Shih ${ }^{1}$}

1 Department of Materials Engineering, Kun Shan University, Tainan 710, Taiwan;

E-Mails: sako_wan@hotmail.com(J.-M.W.); lcchen@mail.ksu.edu.tw (L.-C.C.); precious20091@hotmail.com (I-C.S.)

2 Department of Chemical and Materials Engineering, National Yunlin University of Science and Technology, Yunlin 640, Taiwan; E-Mail: wuty@yuntech.edu.tw

* Author to whom correspondence should be addressed; E-Mail: chenbk@mail.ksu.edu.tw; Tel.: +886-6205-1253; Fax: +886-6205-0493.

External Editor: Michael D. Guiver

Received: 7 September 2014; in revised form: 30 September 2014 / Accepted: 21 October 2014 / Published: 24 October 2014

\begin{abstract}
Proton exchange membranes (PEMs) are a key component of a proton exchange membrane fuel cell. Sulfonated polyimides (SPIs) were doped by protic ionic liquid (PIL) to prepare composite PEMs with substantially improved conductivity. SPIs were synthesized from diamine, 2,2-bis[4-(4-amino-phenoxy)phenyl]propane (BAPP), sulfonated diamine, 4,4'-diamino diphenyl ether-2,2'-disulfonic acid (ODADS) and aromatic anhydride. BAPP improved the mechanical and thermal properties of SPIs, while ODADS enhanced conductivity. A PIL, 1-vinylimidazolium trifluoromethane-sulfonate ([VIm][OTf]), was utilized. [VIm][OTf] offered better conductivity, which can be attributed to its vinyl chemical structure attached to an imidazolium ring that contributed to ionomer-PIL interactions. We prepared sulfonated polyimide/ionic liquid (SPI/IL) composite PEMs using $50 \mathrm{wt} \%$ [VIm][OTf] with a conductivity of $7.17 \mathrm{mS} / \mathrm{cm}$ at $100{ }^{\circ} \mathrm{C}$, and in an anhydrous condition, 3,3',4,4'-diphenyl sulfone tetracarboxylic dianhydride (DSDA) was used in the synthesis of SPIs, leading to several hundred-times improvement in conductivity compared to pristine SPIs.
\end{abstract}

Keywords: proton exchange membrane; sulfonated polyimide; ionic liquid; conductivity 


\section{Introduction}

To reduce global warming, exploring high efficiency energy conversion devices has attracted great interest. Proton exchange membrane fuel cells (PEMFCs) are considered to be the most promising power source for automotive transportation in order to preserve oil resources and significantly reduce greenhouse gas emission [1]. A PEMFC directly converts the chemical energy of hydrogen and oxygen into electricity with a proton exchange membrane (PEM) as a key component. PEMFC has been shown to exhibit effective and high energy conversion, high proton conductivities and excellent energy density [2]. The most commercialized PEM is Nafion ${ }^{\circledR}$, a sulfonated fluoropolymer developed by DuPont. It exhibits high chemical, mechanical and electrochemical stability with high proton conductivity at ambient temperatures. However, the wide application of Nafion PEM is limited, since it does not work well at elevated temperatures and low relative humidity, and there are high costs associated with this product [3].

To improve those shortcomings of Nafion, many researchers are exploring other alternative sulfonated polymers containing poly(ether ketone) [4], poly(ether ether ketone) (PEEK) [5], poly(ether sulfone) [6], polybenzimidazole (PBI) [7] and polyimide [8,9]. Nevertheless, the performances of these alternatives cannot compete against the Nafion membrane. Alternatively, inorganic fillers, such as silica, titanium oxide and boron phosphate, have been applied to membranes [10-12]. Not only have these hydrocarbon-based membranes and inorganic composite membranes been explored, but also the application of protic ionic liquid (PIL) doped into those hydrocarbon-based membranes has been recently studied to promote the performance of PEM above $100{ }^{\circ} \mathrm{C}$ [13-20]. Noto et al. improved the Nafion-based membranes by preparing new materials based on Nafion 117 neutralized with triethylamine (TEA) and doped with the ionic liquids (ILs), triethylammonium trifluoromethanesulfonate [21], triethylammonium methanesulfonate and triethylammonium perfluorobutane sulfonate [22,23].

ILs are molten salts that have attracted much attention in recent years because of their exceptional properties, including high ionic conductivity, a wide liquid temperature range, high thermal and chemical stability, low vapor pressure and high polarity [24,25]. PILs have even higher ionic conductivity than common ILs (which are usually aprotic), and most importantly, PILs are desired due to their intrinsic proton conductivity. Aprotic ILs usually have no proton conductivity unless they are Brønsted acidic [24]. PILs can be tuned by varying the combination of various cations and anions. Che et al. observed that the conductivity of sulfonated PEEK membranes was improved by incorporating trifluoroacetic propylamine, which reached $0.03 \mathrm{~S} \cdot \mathrm{cm}^{-1}$ at $160{ }^{\circ} \mathrm{C}$ under anhydrous conditions [13]. Sulfonated polyimides (SPIs) are used in the electrochemical reaction of oxygen reduction, because they are highly proton-conductive and thermally-, chemically- and physically-stable compounds. Watanabe et al. prepared PEMs for non-humidified fuel cells by the solvent casting method using SPI and a PIL, diethylmethylammonium trifluoromethanesulfonate ([dema][OTf]) [15]. They found that [dema][OTf]-based SPIs had a better hydrogen oxidation reaction and oxygen reduction reaction than that of diethylmethylammonium bis(trifluoromethanesulfonyl) amide. Consequently, the single cell performance of composite membrane with [dema][OTf] demonstrated an open circuit voltage of $0.63 \mathrm{~V}$ and excellent durability within $230 \mathrm{~h}$. Deligöz and Yılmazoğlu [16] synthesized SPI by reacting 2,4-diaminobenzene sulfonic acid (2,4-DABSA) with benzophenontetracarboxylic dianhydride (BTDA) and used IL based on $N$-methylimidazolium tetrafluoroborate to prepare conducting 
composite membranes for high-temperature PEMFCs. They found that the formation of ionic interactions occurred between sulfonic acid groups of SPI and imidazolium groups of PIL. Consequently, the ionic interaction not only provided high ionic conductivity with excellent thermomechanical properties, but also resulted in a positive effect in long-term conductivity stability by blocking IL migration through the membrane. Hwang et al. [18] reported a novel polymer electrolyte membrane using graphene-modified PIL-based composite membrane [denoted PIL(NTFSI)-G] that exhibited dramatic enhancements in ionic conductivity and mechanical properties with only $0.5 \mathrm{wt} \%$ loading of PIL(NTFSI)-G. The research on high conductivity PEM prepared by sulfonated polymers modified with PILs is growing, since the available combinations of polymer and PIL are many.

Recently, we fabricated composite membranes using sulfonated polyimide (SPI) as a matrix polymer and imidazolium PIL to enhance the conductivity of PEMs. SPIs were synthesized from diamine, 2,2-bis[4-(4-amino-phenoxy)phenyl] propane (BAPP) and a sulfonated diamine, 4,4'-diamino diphenyl ether-2,2'-disulfonic acid (ODADS), with an aromatic anhydride, 4,4'-bisphenol A dianhydride (BPADA), or 3,3',4,4'-diphenyl sulfone tetracarboxylic dianhydride (DSDA). The protic ionic liquid used was 1-vinylimidazolium trifluoromethanesulfonate ([VIm][OTf]). This was based on the fact that [VIm][OTf] offered good conductivity, which can be attributed to the vinyl chemical structure attached to an imidazolium ring, as described in our recent study [19]. The benefit of combining SPI with PIL is that the ionic interaction between sulfonic acid groups and imidazolium groups (PIL cation) not only provides structural reinforcement of the polymer matrix at high temperatures, but also limits IL migration and, thus, results in long-term stability of conductivity [16]. We investigated the electrochemical, thermal and mechanical properties of these SPI/IL composite membranes. The aim of this work was to utilize a protic IL in preparation of modified SPI composite membranes to substantially increase the conductivity of PEMs.

\section{Experimental Section}

\subsection{Materials}

Reagent grade chemicals were purchased from commercial sources, including 4,4'-oxydianiline (ODA), 2,2'-bis[4-(4-aminophenoxy)phenyl]propane (BAPP) and 4,4'-bisphenol A dianhydride from Sigma-Aldrich (St. Louis, MO, USA) and 3,3',4,4'-diphenylsulfone tetracarboxylic dianhydride (DSDA) from Tokyo Chemical Inc. (Tokyo, Japan). Dianhydrides were used after thermal treatment in a vacuum at $150{ }^{\circ} \mathrm{C}$ to cyclize possible impurities. $m$-Cresol, concentrated sulfuric acid, fuming sulfuric acid ( $\left.\mathrm{SO}_{3}, 20 \%\right)$, 1-vinylimidazole (99\%), trifluoromethanesulfonic acid (99\%) and diethyl ether were also obtained from Sigma-Aldrich (St. Louis, MO, USA) and were used as received without further purification.

The chemical structure of 1-vinylimidazolium trifluoromethanesulfonate ([VIm][OTf]), is shown in Figure 1. The procedure for synthesizing [VIm][OTf] is described below.

[VIm][OTf] was synthesized by adding trifluoromethanesulfonic acid (1.41 mL, $15.94 \mathrm{mmol})$ dropwise to diethyl ether $(20 \mathrm{~mL})$. A significant amount of heat was given off during the addition, which was performed in an ice bath. 1-Vinylimidazole $(15.94 \mathrm{mmol})$ was then added dropwise with 
stirring in the same ice bath. The IL phase separated and was crystallized after $30 \mathrm{~min}$. The ether was decanted, and the mixture was dried at $353 \mathrm{~K}$ for $24 \mathrm{~h}$ under vacuum $\left(1 \times 10^{-3} \mathrm{mbar}\right)$.

${ }^{1} \mathrm{H}$ NMR (300 MHz, DMSO-d6, ppm): 9.35 (s, 1H, hydrogen of imidazolium, $\mathrm{H}_{2}$ ), $8.17(\mathrm{~s}, 1 \mathrm{H}$, hydrogen of imidazolium, $\mathrm{H}_{4}$ ) and $7.80\left(\mathrm{~s}, 1 \mathrm{H}\right.$, hydrogen of imidazolium, $\left.\mathrm{H}_{5}\right), 7.30$ (dd, $1 \mathrm{H}, J=15.6$, $\left.8.8 \mathrm{~Hz}, \mathrm{~N}-\mathrm{CH}=\mathrm{CH}_{2}\right), 5.97\left(\mathrm{dd}, 1 \mathrm{H}, J=15.6,2.2 \mathrm{~Hz}, \mathrm{~N}-\mathrm{CH}=\mathrm{CH}_{2}\right), 5.41(\mathrm{dd}, 1 \mathrm{H}, J=8.8,2.2 \mathrm{~Hz}$, $\mathrm{N}-\mathrm{CH}=\mathrm{CH}_{2}$ ).

Elem. Anal. Calcd. for $\mathrm{C}_{6} \mathrm{H}_{7} \mathrm{~F}_{3} \mathrm{~N}_{2} \mathrm{O}_{3} \mathrm{~S}$ : C, 29.51\%; H, 2.89\%; N, 11.47\%. Found: C, 29.46\%; $\mathrm{H}, 2.86 \%$; N $11.38 \%$.

Figure 1. Chemical structure of protic ionic liquid (IL) 1-vinylimidazolium trifluoromethane-sulfonate ([VIm][OTf]).<smiles>O=S(=O)([O-])C(F)(F)F</smiles>

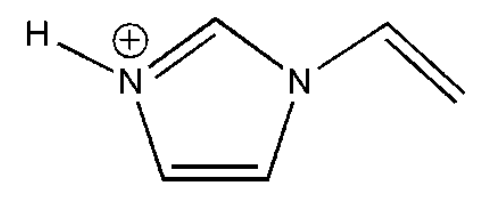

\subsection{Synthesis of 4,4'-Diaminodiphenyl Ether-2,2'-Disulfonic Acid (ODADS)}

The procedure to synthesize ODADS was performed according to the literature [26]. 4,4'-oxydianiline (ODA) was dissolved in concentrated sulfuric acid and then was reacted with dilute fuming sulfuric acid. The mixture slurry was poured into crushed ice. The resulting white precipitate was filtered off and then redissolved in sodium hydroxide solution. The basic solution was filtered, and then, the filtrate was acidified. The solid was filtered off, washed with water and methanol successively and dried at $80^{\circ} \mathrm{C}$ in vacuum. Then, a white product was obtained.

\subsection{Synthesis of Sulfonated Polyimides}

SPIs were synthesized by reacting dianhydride with diamines via chemical imidization through poly(amic acid) (PAA). The code of materials and the amount of diamines, ODADS and BAPP, and dianhydride BPADA used for various SPIs are listed in Table 1. A representative SPIb (ODADS/BAPP/BPADA with a molar ratio $=30 / 20 / 50)$ was prepared as follows:

In a 3-necked 250-mL round-bottom flask equipped with a nitrogen inlet/outlet, vapor trap and a stir motor, ODADS (2.46 g, $6.83 \mathrm{mmol})$, triethylamine (TEA) (2.76 g, $27.3 \mathrm{mmol})$ and $m$-cresol $(25 \mathrm{~mL})$ were mixed. The mixture was heated at $40{ }^{\circ} \mathrm{C}$ until the ODADS was dissolved (about $1.5 \mathrm{~h}$ ). BPADA (5.92 g, $11.38 \mathrm{mmol})$, BAPP (1.87 g, $4.55 \mathrm{mmol})$, benzoic acid (1.97 g, $16.16 \mathrm{mmol})$ and $m$-cresol $(20 \mathrm{~mL})$ were added to the agitated flask, and the temperature was increased to $80{ }^{\circ} \mathrm{C}$ and stirred for $6 \mathrm{~h}$. The temperature was then further increased to $180{ }^{\circ} \mathrm{C}$ and held for $24 \mathrm{~h}$. The reaction mass was cooled to room temperature before pouring it into $500 \mathrm{~g}$ acetone. After blending for $1 \mathrm{~h}$, the mixture was filtered, and the solid was Soxhlet extracted with acetone overnight; then, the solid was vacuum dried at $120{ }^{\circ} \mathrm{C}$ for $24 \mathrm{~h}$. See Scheme 1 for the reaction scheme and the chemical structures of the monomers used. 
Table 1. The codes and mole fractions in the feed of various sulfonated polyimides; SPI, sulfonated polyimide; ODADS, 4,4'-diamino diphenyl ether-2,2'-disulfonic acid; BAPP, 2,2-bis[4-(4-amino-phenoxy)phenyl]propane; BPADA, 4,4'-bisphenol A dianhydride; IEC, ion exchange capacity.

\begin{tabular}{|c|c|c|c|c|c|c|}
\hline \multirow{2}{*}{ Code } & \multicolumn{2}{|c|}{ Diamine mole in feed (mmol) } & \multirow{2}{*}{$\begin{array}{c}\text { Dianhydride } \\
\text { BPADA (mmol) }\end{array}$} & \multirow{2}{*}{$\begin{array}{c}\text { IEC }^{\text {a }}{ }_{\text {(theory) }} \\
(\mathrm{mmol} / \mathrm{g})\end{array}$} & \multirow{2}{*}{$\begin{array}{l}\text { IEC }^{b_{(\exp )}} \\
(\mathrm{mmol} / \mathrm{g})\end{array}$} & \multirow{2}{*}{$\begin{array}{c}\text { Viscosity } \\
\text { (dL/g) }\end{array}$} \\
\hline & ODADS & BAPP & & & & \\
\hline SPIa & 5.69 & 5.69 & 11.38 & 1.03 & 0.93 & 1.169 \\
\hline SPIb & 6.83 & 4.55 & 11.38 & 1.22 & 1.09 & 0.702 \\
\hline SPIc & 7.97 & 3.41 & 11.38 & 1.40 & 1.25 & 0.496 \\
\hline
\end{tabular}

${ }^{\mathrm{a}} \mathrm{IEC}_{(\text {theory) }}$ was calculated from feed monomer ratios; ${ }^{\mathrm{b}} \mathrm{IEC}_{(\mathrm{exp})}$ was measured by titration.

Scheme 1. Reaction scheme of sulfonated polyimides based on BPADA.<smiles>Nc1ccc(Oc2ccc(N)cc2O)c(O)c1</smiles>

ODADS<smiles>CC(C)(C1CCC(OC2CCC(N)CC2)CC1)C1CCC(OC2CCC(N)CC2)CC1</smiles>

BAPP<smiles>CC(C)(c1ccc(Oc2ccc3c(c2)C(=O)OC3=O)cc1)c1ccc(Oc2ccc3c(c2)C(=O)OC3O)cc1</smiles>

BPADA

TEA(Et $\left.{ }_{3} N\right) /$ Benzoic acid / $m$-Cresol

$80^{\circ} \mathrm{C} / 6 \mathrm{~h}, 180^{\circ} \mathrm{C} / 24 \mathrm{~h}$

$-2 \mathrm{n} \mathrm{H}_{2} \mathrm{O}$
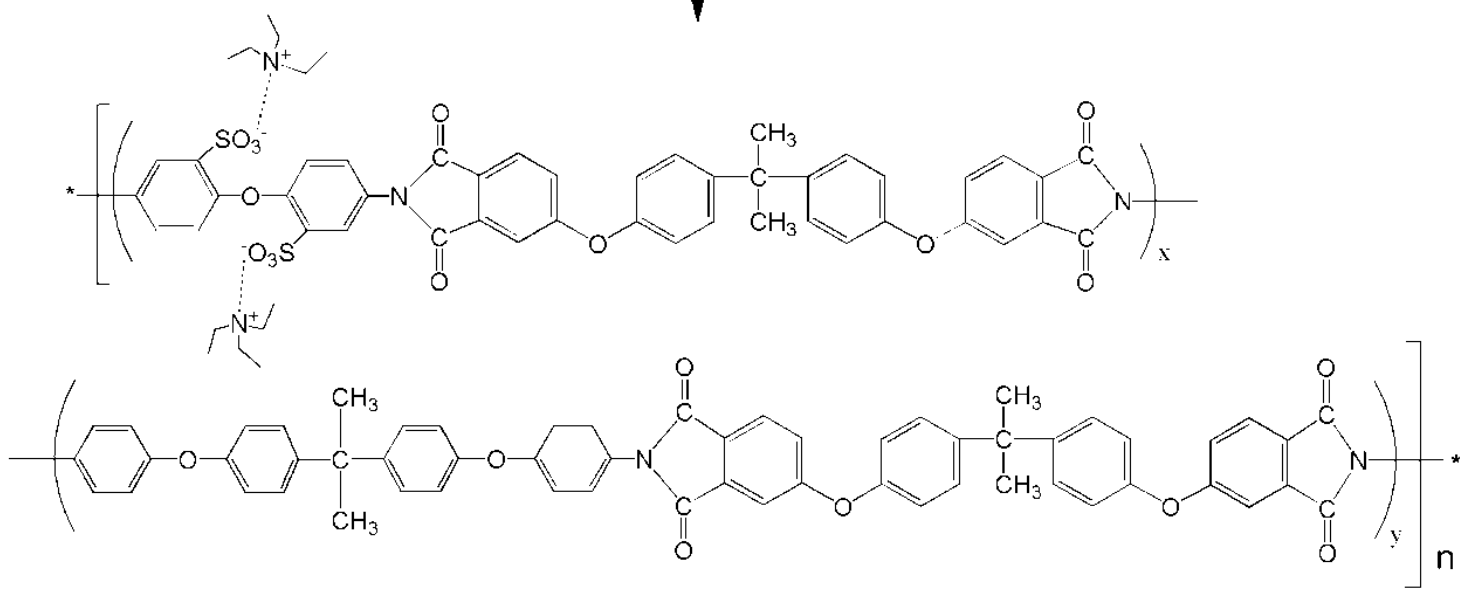

\subsection{Preparation of SPI/IL Composite Membranes}

The composite membranes were prepared using a solution casting method. SPI was first dissolved in $m$-cresol, then appropriate amounts of [VIm][OTf] were added to a sealed sample bottle. The mixture was ultrasonicated for 6-8 h at room temperature to mix completely, and then, it was cast on a Petri dish. Evaporation of $m$-cresol at $60{ }^{\circ} \mathrm{C}$ gave a uniform composite membrane. The composite 
membranes were peeled from the dish, dried in a vacuum oven at $120^{\circ} \mathrm{C}$ overnight, then were cooled to room temperature, and SPI/IL composite membrane films were stored in an inert atmosphere. Table 2 lists codes and weight compositions of sulfonated polyimide/ionic liquid (SPI/IL) composite films.

Table 2. Codes and weight compositions of sulfonated polyimide/ionic liquid (SPI/IL) composite films.

\begin{tabular}{ccc}
\hline Code & SPI & PIL * \\
\hline SPIa/V4 & SPIa 60\% & VIm 40\% \\
SPIb/V4 & SPIb 60\% & VIm 40\% \\
SPIc/V4 & SPIc 60\% & VIm 40\% \\
SPIa/V5 & SPIa 50\% & VIm 50\% \\
SPIb/V5 & SPIb 50\% & VIm 50\% \\
SPIc/V5 & SPIc 50\% & VIm 50\% \\
\hline \multicolumn{3}{c}{ * VIm $=[$ VIm][OTf]. }
\end{tabular}

\subsection{Measurements}

The ion exchange capacity (IEC) was measured by titration. Acidified SPI membranes were vacuum dried until constant weights were obtained. The membranes were then immersed in $50 \mathrm{~mL}$ of saturated $\mathrm{NaCl}$ solution for two days to exchange $\mathrm{H}^{+}$with sodium ions. The liberated $\mathrm{H}^{+}$ions were identified by titration with $0.01 \mathrm{~N} \mathrm{NaOH}$, and phenolphthalein was used as the indicator. The values of IEC were obtained using the following equation:

$$
\operatorname{IEC}(\mathrm{mmol} / \mathrm{g})=\left[C_{\mathrm{NaOH}}\right] V / W_{\text {membrane }}
$$

where $\left[C_{\mathrm{NaOH}}\right]$ is the concentration of $\mathrm{NaOH}, V$ is the volume of $\mathrm{NaOH}$ consumed and $W$ membrane is the weight of dried membrane.

The viscosities were measured at $30{ }^{\circ} \mathrm{C}$ in $m$-cresol by using an Ubbelohde viscometer (Schott Gerate AVS310, Mainz, Germany). ${ }^{1} \mathrm{H}$ nuclear magnetic resonance (NMR) spectra of the synthesized IL and polymers were recorded on BRUKER AV300 and AV400 spectrometers (Billerica, MA, USA), respectively. Fourier transform infrared (FTIR) spectra were recorded on a Bio-Rad Digilab FTS-40 spectrometer (Cambridge, MA, USA). Both the transmission and the attenuated total reflectance (ATR) FTIR spectra were recorded at a resolution of $8 \mathrm{~cm}^{-1}$ and with an accumulation of 16 scans.

The ionic conductivity $(\sigma)$ of the membranes was determined by AC impedance spectroscopy (CH Instruments, CHI 660B, Austin, TX, USA). The membrane was sandwiched between two parallel stainless steel discs $(\phi=1.0 \mathrm{~cm})$. The frequency ranged from $100 \mathrm{kHz}$ to $10 \mathrm{~Hz}$ at a perturbation voltage of $10 \mathrm{mV}$. The ionic conductivity was calculated from the electrolyte resistance $(R)$ obtained from the intercept of the Nyquist plot with the real axis, the membrane thickness $(d)$ and the electrode area $(A)$ according to the equation:

$$
\sigma=d /(A \cdot R)
$$

The error in proton conductivity measurement, caused mainly by the deviation of cell temperature and thickness, was estimated to be less than $10 \%$.

Thermogravimetric analysis (TGA) was performed with a Perkin-Elmer Pyris 1 TGA (Waltham, MA, USA) at a heating rate of $20{ }^{\circ} \mathrm{C} \min ^{-1}$ in $\mathrm{N}_{2}$. Each sample weight was about $5 \mathrm{mg}$. Differential 
scanning calorimetry (DSC) data were obtained from a Perkin-Elmer Pyris Diamond DSC. Samples were scanned at a heating rate of $10{ }^{\circ} \mathrm{C} \min ^{-1}$ under $\mathrm{N}_{2}$. The $T_{\mathrm{g}}$ values were determined from the onset temperature of the change of the specific heat capacity in the heat flow curves. An Instron universal tester (Model 3369, Norwood, MA, USA) was used to study the stress-strain behavior at room temperature. The load cell used was $5 \mathrm{~kg}$, and the crosshead rate was $5 \mathrm{~mm} \mathrm{~min}^{-1}$. Measurements were performed with film specimens ( $1.35 \mathrm{~cm}$ wide, $6 \mathrm{~cm}$ long and 50 60 $\mu \mathrm{m}$ thick). The morphologies of sulfonated polyimides and SPI/IL films were observed with a JEOL JSM-6700 scanning electron microscope (SEM) (Tokyo, Japan).

\section{Results and Discussion}

\subsection{ODA Sulfonation}

ODADS was prepared by direct sulfonation of the parent diamine, ODA, using fuming sulfuric acid as the sulfonating agent [26]. ${ }^{1} \mathrm{H}$ NMR and FTIR spectra were used to confirm the presence of the pendant $-\mathrm{SO}_{3} \mathrm{H}$ group on the monomer structure. From the ${ }^{1} \mathrm{H}$ NMR spectrum, there were three main peaks: $6.42,6.78$ and 7.05 ppm corresponding to $\mathrm{H}$ in the ortho-, meta- and ortho- (next to $\mathrm{SO}_{3} \mathrm{H}$ ) positions of the amino group in a benzene ring. Sulfonation was confirmed by the presence of two sharp IR absorption peaks at 1023 and $1086 \mathrm{~cm}^{-1}$, which were due to the aromatic $\mathrm{SO}_{3} \mathrm{H}$ symmetric and asymmetric stretching vibrations, respectively [19].

${ }^{1} \mathrm{H}$ NMR (400 MHz, DMSO-d6, ppm): 4.29 (4H, br), 6.42 (2H, dd, $J=8.4$ and $\left.2.8 \mathrm{~Hz}\right), 6.78$ (2H, d, $J=8.4 \mathrm{~Hz}), 7.05(2 \mathrm{H}, \mathrm{d}, J=2.8 \mathrm{~Hz})$.

\subsection{Synthesis of Sulfonated Polyimides}

SPIs with various contents of ODADS were synthesized. The FTIR spectra of SPIs are shown in Figure 2. The main intense absorption at $1720-730 \mathrm{~cm}^{-1}$ corresponded to $\mathrm{C}=\mathrm{O}$, and 1378 and $744 \mathrm{~cm}^{-1}$ corresponded to $\mathrm{C}-\mathrm{N}$ stretching and bending peaks, respectively [16]; also, at $1660 \mathrm{~cm}^{-1}$ $(\mathrm{C}=\mathrm{O}(\mathrm{CONH}))$ and $1550 \mathrm{~cm}^{-1}(\mathrm{C}-\mathrm{NH})$, no absorption peaks were observed, which demonstrated the success of imidization. The experimental IECs (by titration) agreed well with those calculated from the feed molar ratios (Table 1). IEC values increased with ODADS content in SPIs. The viscosity of SPIs decreased with increasing content of ODADS (Table 1). Table 3 provides the full assignment of relevant absorption peaks in the FTIR spectra.

The thermal properties of the SPIs were investigated using TGA under a $\mathrm{N}_{2}$ atmosphere at a heating rate of $20^{\circ} \mathrm{C} / \mathrm{min}$. The TGA thermograms (Figure 6) show that there were several stages of weight loss for SPI; the first weight loss that occurred between 100 and $250{ }^{\circ} \mathrm{C}$ was attributable to the degradation of the attached sulfonic acid groups [27]; and the second weight loss that occurred between 300 and $380{ }^{\circ} \mathrm{C}$ originated from the decomposition of the polyimide side chains. Finally, degradation occurred at temperatures higher than $450{ }^{\circ} \mathrm{C}$ due to the decomposition of polyimide main chains. Table 4 showed that the thermal decomposition temperature $\left(T_{\mathrm{d}}\right)$ and glass transition temperature $\left(T_{\mathrm{g}}\right)$ decreased with the increasing amount of ODADS in SPIs, which indicated that ODADS reduced the thermal stability while softening SPIs. 
Figure 2. FTIR spectra of SPIs.

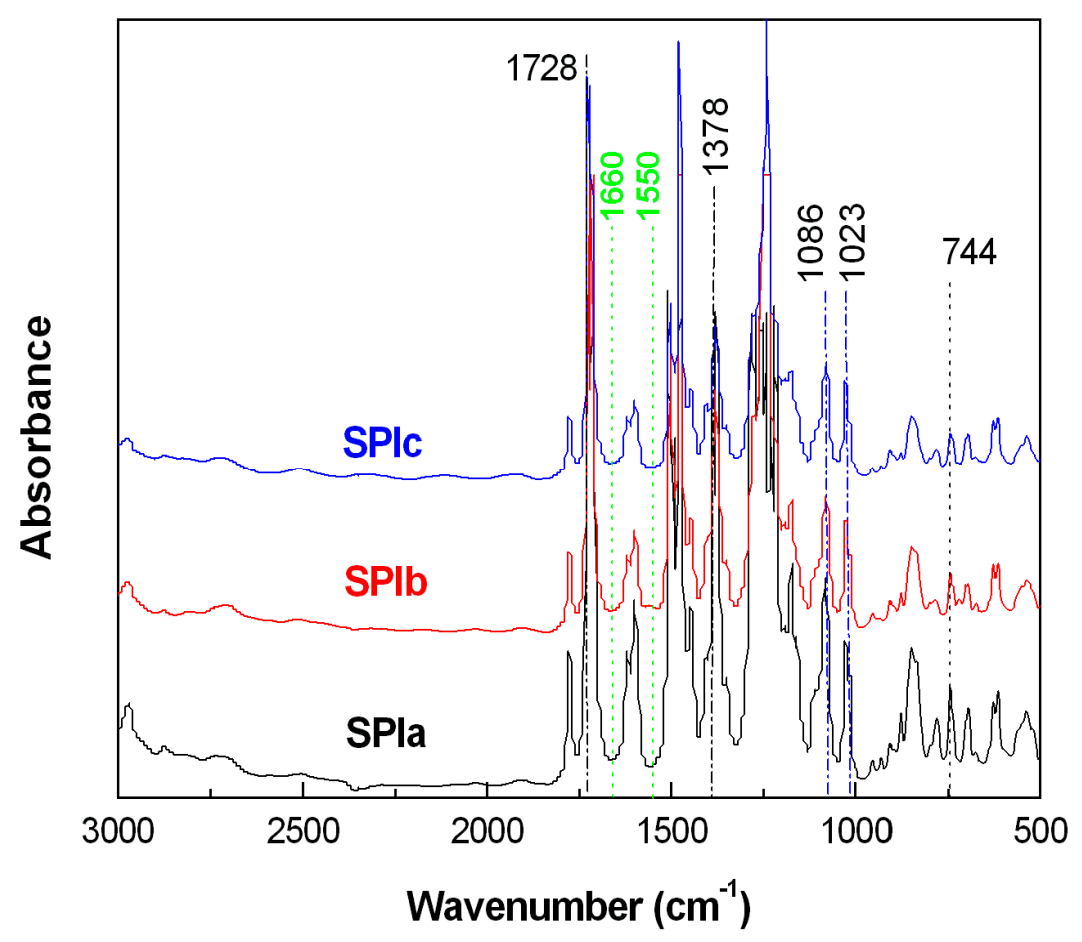

Table 3. FTIR absorptions.

\begin{tabular}{cccc}
\hline Compound & Absorption Band $\left(\mathbf{c m}^{-1}\right)$ & Intensity * & Origin ** \\
\hline \multirow{3}{*}{ Disulfonic acid } & $1086 \mathrm{~cm}^{-1}$ & $\mathrm{~s}$ & $-\mathrm{SO}_{3} \mathrm{H}$, asym. stretch \\
& $1023 \mathrm{~cm}^{-1}$ & $\mathrm{~s}$ & $-\mathrm{SO}_{3} \mathrm{H}$, sym. stretch \\
& $1618 \mathrm{~cm}^{-1}, 3442 \mathrm{~cm}^{-1}$ & $\mathrm{~m}, \mathrm{~s}$ & $-\mathrm{NH}_{2}$ stretch \\
\hline \multirow{5}{*}{ Sulfonated Polyimides } & $1779 \mathrm{~cm}^{-1}$ & $\mathrm{~s}$ & $\mathrm{C}=\mathrm{O}$ asym. stretch \\
& $1728 \mathrm{~cm}^{-1}$ & $\mathrm{vs}$ & $\mathrm{C}=\mathrm{O}$ sym. stretch \\
& $2960 \mathrm{~cm}^{-1}-2850 \mathrm{~cm}^{-1}$ & $\mathrm{~s}$ & $\mathrm{CH}_{2}$ band \\
& $1378 \mathrm{~cm}^{-1}$ & $\mathrm{~s}$ & $\mathrm{C}-\mathrm{N}$ stretch \\
& $744 \mathrm{~cm}^{-1}$ & - & $\mathrm{C}=\mathrm{O}$ bending \\
Amic acids & $1275 \mathrm{~cm}^{-1}-1200 \mathrm{~cm}^{-1}$ & $\mathrm{~s}$ & $\mathrm{C}-\mathrm{O}-\mathrm{C}$ stretch \\
& $2697 \mathrm{~cm}^{-1}$ & $\mathrm{~m}$ & $\left(\mathrm{C}_{2} \mathrm{H}_{5}\right)_{3} \mathrm{~N}$ \\
\hline \multirow{2}{*}{ Ionic liquids } & $1660 \mathrm{~cm}^{-1}$ & $\mathrm{~s}$ & $\mathrm{C}=\mathrm{O}(\mathrm{CONH})$ \\
& $1710 \mathrm{~cm}^{-1}$ & $\mathrm{~s}$ & $\mathrm{C}=\mathrm{O}(\mathrm{COOH})$ \\
& $1550 \mathrm{~cm}^{-1}$ & $\mathrm{w}$ & $\mathrm{C}-\mathrm{NH}$ \\
\hline
\end{tabular}

$*$ vs $=$ very strong; $\mathrm{s}=$ strong; $\mathrm{m}=$ medium; $\mathrm{w}=$ weak; $\mathrm{v}=$ variable; $* *$ asym. $=$ asymmetric; sym. $=$ symmetric.

\subsection{Characterization of Composite Membranes}

The ionic liquid modified composite membranes were fabricated using the solution casting method with $m$-cresol as the casting solvent. The FTIR spectra of composite membranes are shown in Figure 3. SPI/IL composite membranes exhibited two sharp absorption peaks at 1023 and $1086 \mathrm{~cm}^{-1}$, which were due to the aromatic - $\mathrm{SO}_{3} \mathrm{H}$ symmetric and asymmetric stretching vibrations of SPI, respectively, and characteristic aromatic $\mathrm{C}-\mathrm{H}$ stretching of the imidazolium cation near $3165 \mathrm{~cm}^{-1}$ [28]. The 
absorption at $1547 \mathrm{~cm}^{-1}$ was attributed to cationic $\mathrm{C}=\mathrm{N}$ in ionic liquid [24]; while a peak at $1660 \mathrm{~cm}^{-1}$ referred to the unique $\mathrm{N}-\mathrm{C}=\mathrm{C}$ absorption of [VIm][OTf]. The absorption peaks from the anion of IL were in the range of 500 to $1571 \mathrm{~cm}^{-1}$. The broadening of the bands in the region of $2400-3300 \mathrm{~cm}^{-1}$ is attributed to the hydrogen bonding between the $-\mathrm{SO}_{3}{ }^{-}$of the anion and $-\mathrm{NH}^{+}$of the cation in [VIm][OTf] [29]. The FTIR spectra shown in Figure 3 further indicated the formation of SPI/IL composite membranes. All of the spectroscopic data obtained were in agreement with the chemical structures.

Figure 3. FTIR spectra of SPIb, [VIm][OTf] and SPI/IL composite films.

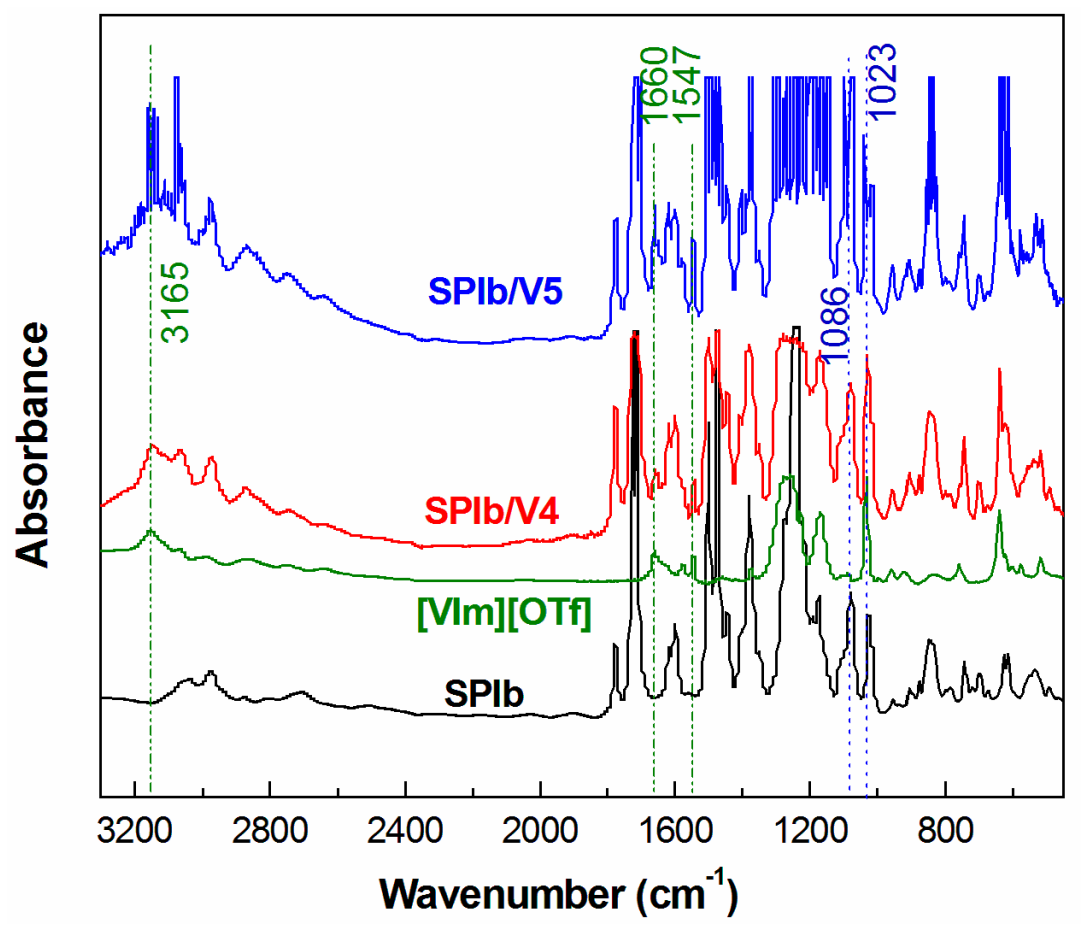

\subsection{Membrane Conductivity}

The membranes comprised of a polymer with sulfonic acid groups exhibited higher ionic conductivities than those comprised of neutral polymers [30]. As expected, SPIc had the highest ionic conductivity among SPIs studied at all temperatures, since it contained more sulfonic acid groups (IEC $=1.40 \mathrm{mmol} / \mathrm{g}$; Table 1$)$. Proton conductivity was generally thermally stimulated, and it was reasonable to observe an increase in conductivity with increasing temperature (Figure 4). However, SPIc only had ionic conductivity of $2.83 \times 10^{-3} \mathrm{mS} / \mathrm{cm}$ at $120{ }^{\circ} \mathrm{C}$ under non-humidified conditions, since the conductivity of SPI is water dependent, which makes conductivity very low, even at high temperatures [16]. To improve the conductivity of PEMs, we doped the SPIs with a PIL, [VIm][OTf]. As shown in Figure 4, the conductivity of composite membranes increased substantially. Higher amounts of ionic liquid in the composite system were expected to further improve ionic conductivity. SPIc/V5 had the highest ionic conductivity among all SPI/IL composite films studied at all temperatures. A proton conductivity of $2.66 \mathrm{mS} / \mathrm{cm}$ at $120{ }^{\circ} \mathrm{C}$ was observed. This demonstrated an almost 1000-times improvement in conductivity, which can be attributed to the chemical structure of [VIm][OTf], which has a vinyl group attached to an imidazolium ring, though being less stable at high 
temperatures. It provides a lower melting point $\left(64.3^{\circ} \mathrm{C}\right)$ and led to better ionomer-PIL interactions, which plays a major role in determining the conductivity of the IL-doped SPI membranes [31]. Conductivities of membranes in anhydrous atmosphere depended on temperature, ionic liquid concentration in the membrane, the type of polymer matrix [16] and the possible interactions between ILs and polymers [21,32].

Figure 4 shows the Arrhenius plot for the temperature-dependent conductivities, which shows that the SPI/IL composites deviated slightly from Arrhenius-like behavior. The Vogel-Fulcher-Tammann (VFT) equation can be utilized to fit the data [29,33].

Figure 4. Temperature dependence of conductivity of SPIs and SPI/IL composite membranes.

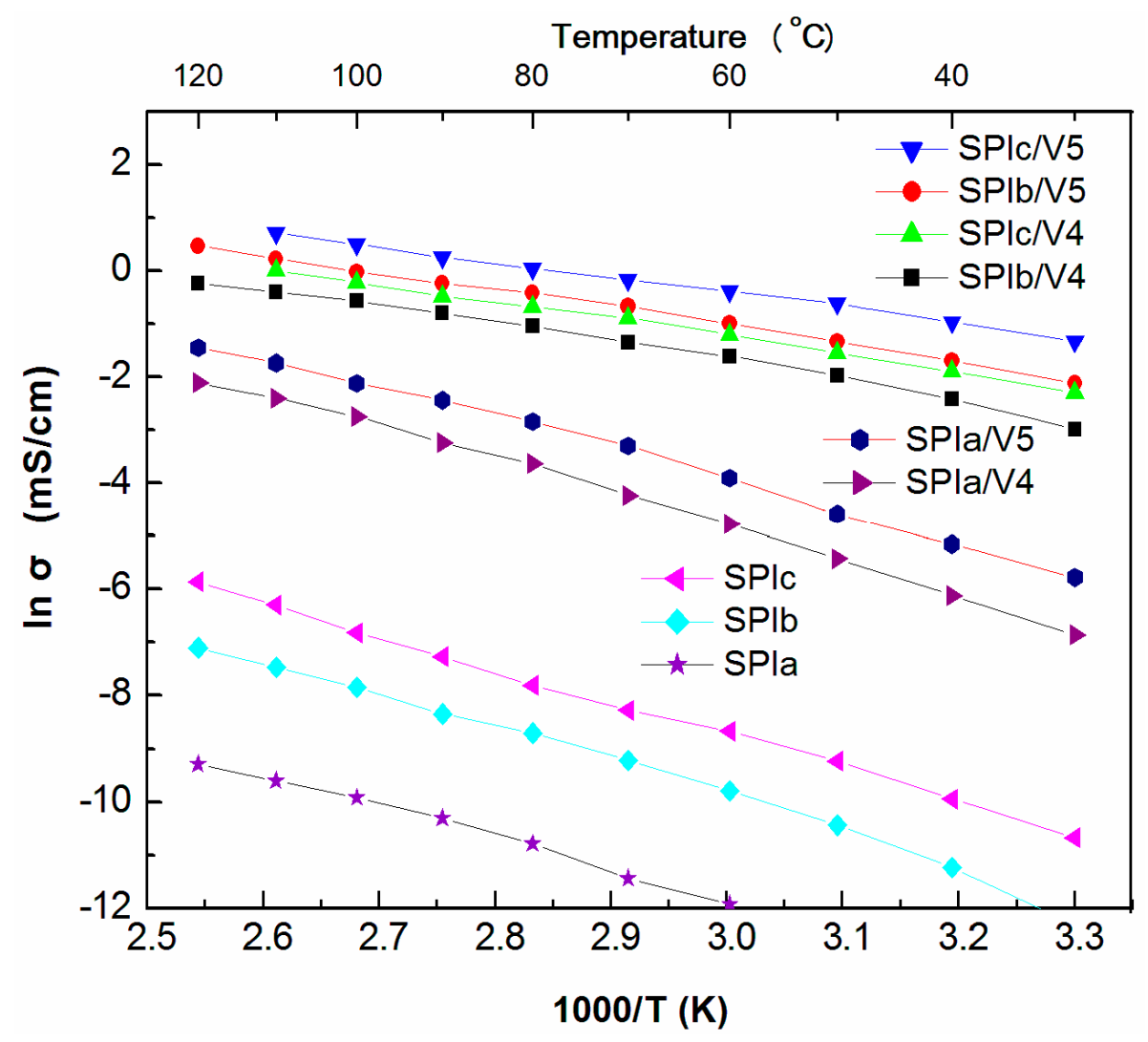

\subsection{Membrane Morphology}

The SPI and SPI/IL composite membrane films are flexible and transparent. With the increase of IL loading, the color of the films became slightly darker. The morphologies of SPIs, IL and SPL/IL composite membranes were analyzed by SEM under ambient conditions, as illustrated in Figure 5. The SEM image of SPIs showed a flat topography (Figure 5a), and [VIm][OTf] had a "rough" and crystalline morphology (Figure 5b), while the images of SPI/ILs showed a homogeneous ionic liquid dispersed morphology (Figure 5c,d). SPIc/V5 (with more ODADS content) demonstrated better dispersion than SPIb/V5. The cross-sectional view of SPI/IL films demonstrated a dense membrane. The morphology of the membrane containing hydrophilic IL moieties, e.g., [OTf], showed better connectivity than the membrane containing a hydrophobic IL, resulting in higher conductivity [34]. This suggests that morphology plays an important role in IL-based membrane design. Sekhon et al. concluded that both the hydrophilicity of impregnated ionic liquids and the structure of the polymer 
matrix affect the morphology of formed membranes, which is directly related to the ionic conductivity of membranes [14].

Figure 5. SEM morphology of (a) SPI, (b) IL and (c,d) SPI/IL composite membranes.

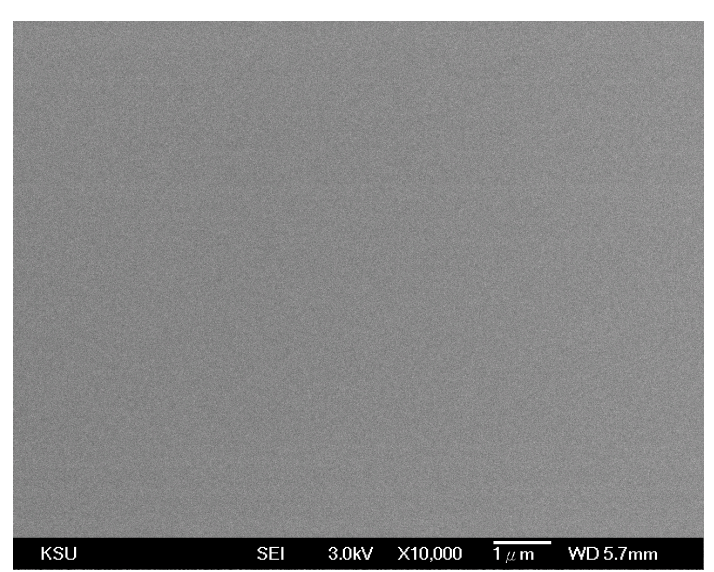

(a) SPIb

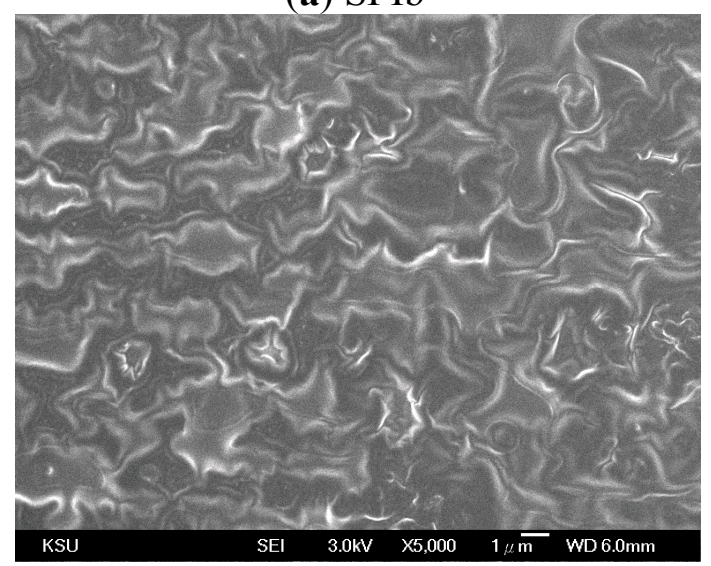

(c) $\mathrm{SPIb} / \mathrm{V} 5$

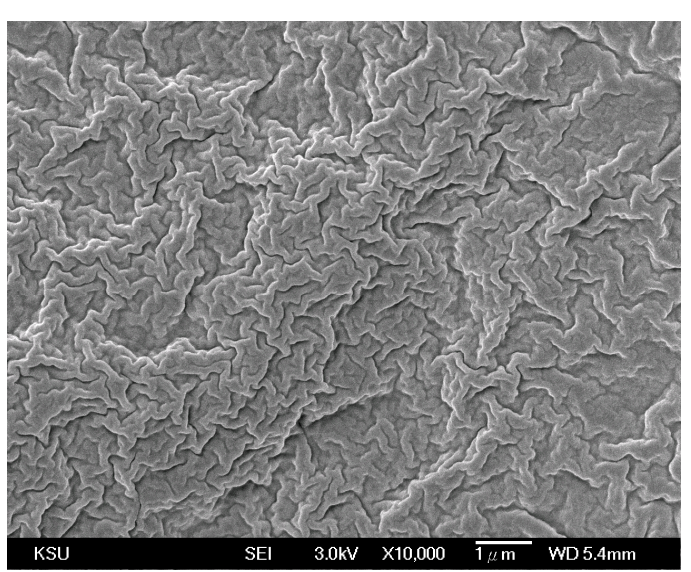

(b) $[\mathrm{VIm}][\mathrm{OTf}]$

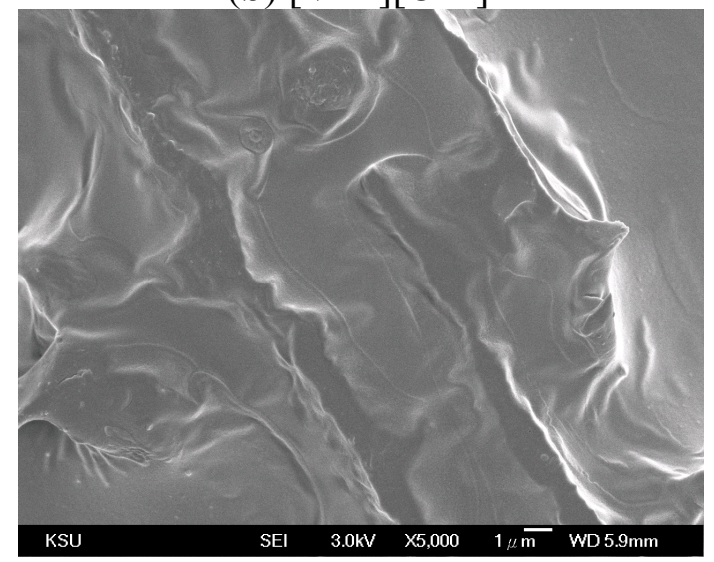

(d) $\mathrm{SPIc} / \mathrm{V} 5$

\subsection{Thermal Properties}

TGA and DSC have been vital techniques used to study the thermal behavior of polymers. The corresponding thermal data, thermal decomposition temperatures and glass transition temperatures $\left(T_{\mathrm{g}}\right)$ are listed in Table 4 . The combination of SPI with ionic liquids resulted in membranes displaying higher thermal stabilities than pristine SPI polymers (Table 4). This improvement can be observed in thermograms. Incorporation of [VIm][OTf] in the composite films resulted in almost nil weight loss before $300{ }^{\circ} \mathrm{C}$. This is about the onset of degradation for the ionic liquid used. However, this (decomposition) temperature is still well above the operating temperature of a high temperature PEMFC (100-200 $\left.{ }^{\circ} \mathrm{C}\right)$. The thermal data indicated that the SPI/IL composite films had high thermal stability. As the thermal data showed, the $T_{\mathrm{g}}$ decreased with increasing amounts of ODADS and IL contents in SPI/IL composite membranes. Clearly, the $T_{\mathrm{g}}$ of SPI/IL composite membranes decreased substantially compared with pristine SPI membranes. The TGA data also showed that [VIm][OTf] has a larger amount of residues at high temperatures (Figure 6). This might be attributed to the vinyl chemical structure of [VIm][OTf], which can be oligomerized or polymerized at $200{ }^{\circ} \mathrm{C}$ or higher temperatures [35]. 
Table 4. Thermal and mechanical properties of SPIs, IL and SPI/IL composite membranes.

\begin{tabular}{ccccc}
\hline Material & $\boldsymbol{T}_{\mathbf{d}-\mathbf{1 0} \%}\left({ }^{\circ} \mathbf{C}\right)$ & $\boldsymbol{T}_{\mathbf{g}}\left({ }^{\circ} \mathbf{C}\right)$ & Tensile Strength (MPa) & Elongation at Break (\%) \\
\hline SPIa & 389.1 & 299.2 & $57.5 \pm 3.4$ & $4.9 \pm 0.4$ \\
SPIb & 369.7 & 298.2 & $42.1 \pm 2.7$ & $5.2 \pm 0.6$ \\
SPIc & 359.1 & 297.7 & $34.9 \pm 1.8$ & $10.1 \pm 2.8$ \\
SPIa/V4 & 381.2 & 132.8 & $15.6 \pm 1.2$ & $27.7 \pm 3.8$ \\
SPIb/V4 & 377.5 & 128.3 & $13.0 \pm 0.9$ & $47.0 \pm 5.3$ \\
SPIc/V4 & 371.3 & 113.6 & $8.6 \pm 1.0$ & $117 \pm 19.0$ \\
SPIa/V5 & 380.8 & 129.8 & $13.4 \pm 1.3$ & $39.9 \pm 4.4$ \\
SPIb/V5 & 376.3 & 126.4 & $9.2 \pm 0.7$ & $103 \pm 12.1$ \\
SPIc/V5 & 372.4 & 110.0 & $5.6 \pm 0.8$ & $124 \pm 24.3$ \\
{$[$ VIm][OTf] } & 376.2 & 50.0 & - & - \\
\hline \multicolumn{5}{c}{}
\end{tabular}

Figure 6. TGA scans of SPIb, ILs and SPIb/IL composite membranes.

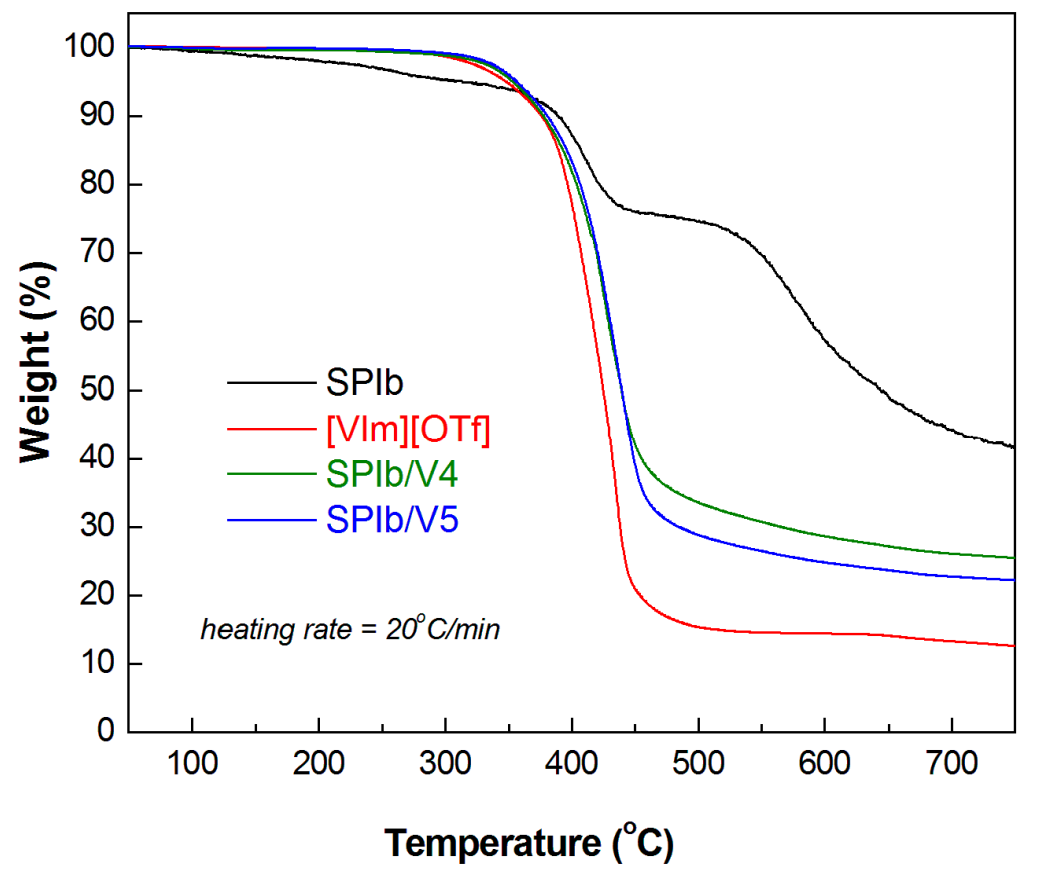

\subsection{Mechanical Properties}

Polyimides have good mechanical properties [36], while sulfonated materials are tough materials and exhibit certain extendibility, depending on the contents of the sulfonated component (ODADS). Table 4 shows that tensile strength decreases and strain increases with increasing amount of ODADS in SPIs. The mechanical properties exhibit a similar trend as the thermal properties for SPIs.

SPI/IL composite films, however, demonstrated markedly increased ductility, as shown in Table 4. The prepared SPI/IL composite materials had a very high elongation at break (increased by 6-20 times when compared to SPI), but had lower tensile strength. The ultimate strain in modified samples increased with the addition of ionic liquids. The SPI/IL materials all had observed yield points, for the SPIb modified with $50 \%$ [VIm] [OTf] had an elongation at break that increased from $5 \%$ to $103 \%$ and 
tensile stress that decreased from 42 to $9.2 \mathrm{MPa}$. The increase in the ductile mechanical property can be attributed to the vinyl structure of [VIm][OTf].

The composite membranes possessed good thermal stability and high ionic conductivity, but were usually accompanied by reduced mechanical strength and dimensional stability at elevated temperatures. Increasing the polymer content lead to the improvement of mechanical properties, but was accompanied by a reduction in ionic conductivity. As discussed above, the $T_{\mathrm{g}}$ of SPIc/IL composite membranes were similar to or lower than the operating temperature of an intermediate temperature PEMFC $\left(120{ }^{\circ} \mathrm{C}\right)$. Therefore, for practical purposes, it is suggested that SPIb be blended with [VIm][OTf].

\subsection{Comparison of Effect of Dianhydride on SPI}

In this study, we first used BPADA as the dianhydride to prepare SPI. The conductivity of PEM prepared from this SPI is less effective when compared to SPI utilizing 4,4'-oxydiphthalic anhydride (ODPA) as the dianhydride (presented in our recent study [19]). For SPIb/V5 at $100{ }^{\circ} \mathrm{C}$, the conductivity is $0.98 \mathrm{mS} / \mathrm{cm}$ for BPADA as the dianhydride $v s .2 .08 \mathrm{mS} / \mathrm{cm}$ for ODPA, respectively. These results indicate that ODPA is a better dianhydride than BPADA in the preparation of SPI for use as PEM. To improve the conductivity of the PEM of our SPI system, we recently investigated DSDA as the dianhydride (Figure 7) to prepare SPI. The result showed in Figure 8 demonstrated that the conductivity of SPI/IL PEM prepared from DSDA is much higher than that made from BPADA and better than that from ODPA. An SPIb/V5 composite PEM using DSDA as the dianhydride and $50 \mathrm{wt} \%$ [VIm][OTf] was prepared via a similar procedure, and a conductivity of $7.17 \mathrm{mS} / \mathrm{cm}$ was obtained at $100{ }^{\circ} \mathrm{C}$ and in an anhydrous condition. This can be attributed to the chemical structure variation of these dianhydrides; DSDA has a sulfonyl group. This illustrated the important role the dianhydride played in the conductivity of PEM. We are currently investigating the effect of various dianhydrides on the performance of sulfonated polyimides to be used as PEM.

Figure 7. Chemical structure of dianhydrides. ODPA, 4,4'-oxydiphthalic anhydride; DSDA, 3,3',4,4'-diphenyl sulfone tetracarboxylic dianhydride.<smiles>O=C1OC(=O)c2cc(Oc3ccc4c(c3)C(=O)OC4=O)ccc21</smiles>

ODPA<smiles>O=C1OC(=O)c2cc(S(=O)(=O)c3ccc4c(c3)C(=O)OC4=O)ccc21</smiles>

DSDA 
Figure 8. Temperature dependence of the conductivity of SPIb/V5 composite membranes and pristine SPIb membranes made by various dianhydrides. The conductivity data of composite membranes made from dianhydride ODPA (curve "ODPA") were from [19].

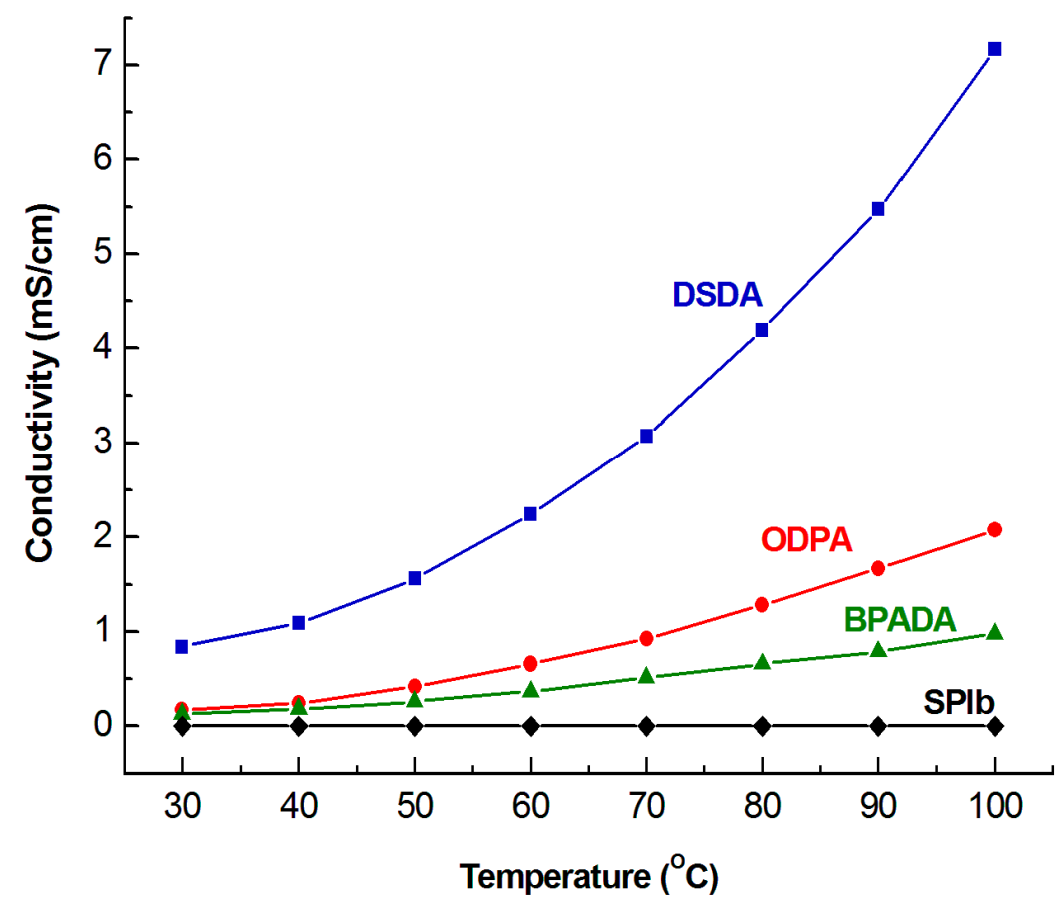

\section{Conclusions}

Protic IL-doped SPI composite membranes were prepared and characterized as potential proton exchange membrane (PEM) materials. SPIs were synthesized from sulfonated diamine, 4,4'-diaminodiphenyl ether-2,2'-disulfonic acid (ODADS), diamine, 2,2-bis[4-(4-amino-phenoxy)phenyl] propane (BAPP) and an aromatic anhydride, BPADA or DSDA. ODADS improved conductivity, while BAPP enhanced the mechanical and thermal properties of SPIs. Blending SPIs with PIL [VIm][OTf] substantially increased the conductivity of PEMs with nearly 1000-times improvement. The composite membranes exhibited good thermal stability and high ionic conductivity under anhydrous conditions, compared to pristine SPI membranes. [VIm][OTf] offered good conductivity, which could be attributed to the vinyl chemical structure attached to an imidazolium ring that contributed to ionomer-PIL interactions. This played a major role in improving the conductivity of the SPI/IL composite PEMs. Further work will involve the investigating of other SPIs with various diamines/dianhydrides to improve the conductivity of PEM and testing of these prepared membranes in hydrogen/oxygen fuel cells.

\section{Acknowledgments}

Financial support from the Ministry of Science and Technology of Taiwan (MOST 103-2221-E-168-033) is gratefully appreciated. 


\section{Author Contributions}

Bor-Kuan Chen wrote the paper, Jhong-Ming Wong performed polymer syntheses, characterizations, and TGA, DSC experiments, I-Chao Shih performed the IEC and conductivity measurements, Tzi-Yi Wu and Lung-Chuan Chen provided the guidance of experiments.

\section{Conflicts of Interest}

The authors declare no conflict of interest.

\section{References}

1. Ye, Y.S.; Rick, J.; Hwang, B.J. Water soluble polymers as proton exchange membranes for fuel cells. Polymers 2012, 4, 913-963.

2. Choi, S.W.; Park, J.O.; Pak, C.; Choi, K.H.; Lee, J.C.; Chang, H. Design and synthesis of cross-linked copolymer membranes based on poly(benzoxazine) and polybenzimidazole and their application to an electrolyte membrane for a high-temperature PEM fuel cell. Polymers 2013, 5, 77-111.

3. Zaidi, S.M.J. Research trends in polymer electrolyte membranes for PEMFC. In Polymer Membranes for Fuel Cells; Zaidi, S.M.J., Matsuura, T., Eds.; Springer Publishing Co.: New York, NY, USA, 2006; pp. 7-25.

4. Kreuer, K.D. On the development of proton conducting polymer membranes for hydrogen and methanol fuel cells. J. Membr. Sci. 2001, 185, 29-39.

5. Li, W.; Zhang, F.; Yi, S.; Huang, C.; Zhang, H.; Pan, M. Effects of casting solvent on microstructrue and ionic conductivity of anhydrous sulfonated poly(ether ether ketone)-inoic liquid composite membranes. Int. J. Hydrog. Energy 2012, 37, 748-754.

6. Krishnan, N.N.; Kim, H.J.; Jang, J.H.; Cho, E.A.; Lee, S.Y.; Lim, T.H.; Hong, S.A. Fuel cell performance of polymer electrolyte membrane based on hexafluorinated sulfonated poly(ether sulfone). Polym. Bull. 2009, 62, 457-468.

7. Li, Q.; Pan, C.; Jensen, J.O.; Noye, P.; Bjerrum, N.J. Cross-linked polybenzimidazole membranes for fuel cells. Chem. Mater. 2007, 19, 350-352.

8. Zhu, X.; Pan, H.; Liang, Y.; Jian, X. Synthesis and properties of novel sulfonated polyimides containing phthalazinone moieties for PEMFC. Eur. Polym. J. 2008, 44, 3782-3789.

9. Yan, J.; Liu, C.; Wang, Z.; Xing, W.; Ding, M. Water resistant sulfonated polyimides based on 4,4'-binaphthyl-1,1',8,8'-tetracarboxylic dianhydride (BNTDA) for proton exchange membranes. Polymer 2007, 48, 6210-6214.

10. Su, Y.H.; Liu, Y.L.; Sun, Y.M.; Lai, J.Y.; Guiver, M.D.; Gao, Y. Using silica nanoparticles for modifying sulfonated poly(phthalazinone ether ketone) membrane for direct methanol fuel cell: A significant improvement on cell performance. J. Power Sources 2006, 155, 111-117.

11. Nunes, S.P.; Ruffmann, B.; Rikowski, E.; Vetter, S.; Richau, K. Inorganic modification of proton conductive polymer membranes for direct methanol fuel cells. J. Membr. Sci. 2002, 203, 215-225.

12. Zaidi, S.M.J.; Rahman, S.U. Perfluorinated ionomer-boron phosphate composite membranes for DMFC applications. J. Electrochem. Soc. 2005, 152, A1590-A1594. 
13. Che, Q.T.; Sun, B.Y.; He, R.H. Preparation and characterization of new anhydrous, conducting membranes based on composites of ionic liquid trifluoroacetic propylamine and polymers of sulfonated poly (ether ether) ketone or polyvinylidenefluoride. Electrochim. Acta 2008, 53, 4428-4434.

14. Sekhon, S.S.; Park, J.S.; Cho, E.K.; Yoon, Y.G.; Kim, C.S.; Lee, W.Y. Studies of high temperature proton conducting membranes containing hydrophilic/hydrophobic ionic liquids. Macromolecules 2009, 42, 2054-2062.

15. Yasuda, T.; Nakamura, S.; Honda, Y.; Kinugawa, K.; Lee, S.Y.; Watanabe, M. Effects of polymer structure on properties of sulfonated polyimide/protic ionic liquid composite membranes for nonhumidified fuel cell applications. ACS Appl. Mater. Interfaces 2012, 4, 1783-1790.

16. Deligöz, H.; Yılmazoğlu, M. Development of a new highly conductive and thermomechanically stable complex membrane based on sulfonated polyimide/ionic liquid for high temperature anhydrous fuel cells. J. Power Sources 2011, 196, 3496-3502.

17. Xiang, J.; Chen, R.; Wu, F.; Li, L.; Chen, S.; Zou, Q. Physicochemical properties of new amide-based protic ionic liquids and their use as materials for anhydrous proton conductors. Electrochim. Acta 2011, 56, 7503-7509.

18. Ye, Y.S.; Tseng, C.Y.; Shen, W.C.; Wang, J.S.; Chen, K.J.; Cheng, M.Y.; Rick, J.; Huang, Y.J.; Chang, F.C.; Hwang, B.J. A new graphene-modified protic ionic liquid-based composite membrane for solid polymer electrolytes. J. Mater. Chem. 2011, 21, 10448-10453.

19. Chen, B.K.; Wu, T.Y.; Kuo, C.W.; Peng, Y.C.; Shih, I.C.; Hao, L.; Sun, I.W. 4,4'-Oxydianiline (ODA) containing sulfonated polyimide/protic ionic liquid composite membranes for anhydrous proton conduction. Int. J. Hydrog. Energy 2013, 38, 11321-11330.

20. Luo, J.; Conrad, O.; Vankelecom, I.F.J. Imidazolium methanesulfonate as a high temperature proton conductor. J. Mater. Chem. A 2013, 1, 2238-2247.

21. Di Noto, V.; Negro, E.; Sanchez, J.-Y.; Iojoiu, C. Structure-relaxation interplay of a new nanostructured membrane based on tetraethylammonium trifluoromethanesulfonate ionic liquid and neutralized nafion 117 for high-temperature fuel cell. J. Am. Chem. Soc. 2010, 132, 2183-2195.

22. Di Noto, V.; Piga, M.; Giffin, G.A.; Lavina, S.; Smotkin, E.S.; Sanchez, J.-Y.; Iojoiu, C. Influence of anions on proton-conducting membranes based on neutralized nafion 117, triethylammonium methanesulfonate, and triethylammonium perfluorobutanesulfonate. 1. Synthesis and properties. J. Phys. Chem. C 2012, 116, 1361-1369.

23. Di Noto, V.; Piga, M.; Giffin, G.A.; Lavina, S.; Smotkin, E.S.; Sanchez, J.; Iojoiu, C. Influence of anions on proton-conducting membranes based on neutralized nafion 117, triethylammonium methanesulfonate, and triethylammonium perfluorobutanesulfonate. 2. Electrical properties. J. Phys. Chem. C 2012, 116, 1370-1379.

24. Luo, J.; Hu, J.; Saak, W.; Beckhaus, R.; Wittstock, G.; Vankelecom, I.F.J.; Agerta, C.; Conrad, O. Protic ionic liquid and ionic melts prepared from methanesulfonic acid and 1H-1,2,4-triazole as high temperature PEMFC electrolytes. J. Mater. Chem. 2011, 21, 10426-10436.

25. Chen, B.K.; Wu, T.Y.; Chang, Y.M.; Chen, A.F. Ductile polylactic acid prepared with ionic liquids. Chem. Eng. J. 2013, 215-216, 886-893. 
26. Fang, J.; Guo, X.; Harada, S.; Watari, T.; Tanaka, K.; Kita, H.; Okamoto, K. Novel sulfonated polyimides as polyelectrolytes for fuel cell application. 1. Synthesis, proton conductivity, and water stability of polyimides from 4,4'-diamino diphenyl ether-2,2'-disulfonic acid. Macromolecules 2002, 35, 9022-9028.

27. Di Noto, V.; Boaretto, N.; Negro, E.; Giffin, G.A.; Lavina, S.; Polizzi, S. Inorganic-organic membranes based on Nafion, $\left[\left(\mathrm{ZrO}_{2}\right) \cdot\left(\mathrm{HfO}_{2}\right)_{0.25}\right]$ and $\left[\left(\mathrm{SiO}_{2}\right) \cdot\left(\mathrm{HfO}_{2}\right)_{0.28}\right]$. Part I: Synthesis, thermal stability and performance in a single PEMFC. Int. J. Hydrog. Energy 2012, 37, 6199-6214.

28. Luo, J.; Tan, T.V.; Conrad, O.; Vankelecom, I.F.J. 1H-1,2,4-Triazole as solvent for imidazolium methanesulfonate. Phys. Chem. Chem. Phys. 2012, 14, 11441-11447.

29. Luo, J.; Conrad, O.; Vankelecom, I.F.J. Physicochemical properties of phosphonium-based and ammonium-based protic ionic liquids. J. Mater. Chem. 2012, 22, 20574-20579.

30. Higashihara, T.; Matsumoto, K.; Ueda, M. Sulfonated aromatic hydrocarbon polymers as proton exchange membranes for fuel cells. Polymer 2009, 50, 5341-5357.

31. Ohno, H. Electrochemical Aspects of Ionic Liquids; Wiley Interscience: Hoboken, NJ, USA, 2005.

32. Martinelli, A.; Matic, A.; Jacobsson, P.; Borjesson, L.; Fernicola, A.; Panero, S.; Scrosati, B.; Ohno, H. Physical properties of proton conducting membranes based on a protic ionic liquid. J. Phys. Chem. B 2007, 111, 12462-12467.

33. Wu, T.Y.; Chen, B.K.; Hao, L.; Lin, K.F.; Sun, I.W. Thermophysical properties of a room temperature ionic liquid (1-methyl-3-pentyl-imidazolium hexafluorophosphate) with poly(ethylene glycol). J. Taiwan Inst. Chem. Eng. 2011, 42, 914-921.

34. Ye, Y.S.; Rick, J.; Hwang, B.J. Ionic liquid polymer electrolytes. J. Mater. Chem. A 2013, 1, 2719-2743.

35. Hirao, M.; Ito, K.; Ohno, H. Preparation and polymerization of new organic molten salts; $N$-alkylimidazolium salt derivatives. Electrochim. Acta 2000, 45, 1291-1294.

36. Chen, B.K.; Su, C.T.; Tseng, M.C.; Tsay, S.Y. Preparation of polyetherimide nanocomposites with improved thermal, mechanical and dielectric properties. Polym. Bull. 2006, 57, 671-681.

(C) 2014 by the authors; licensee MDPI, Basel, Switzerland. This article is an open access article distributed under the terms and conditions of the Creative Commons Attribution license (http://creativecommons.org/licenses/by/4.0/). 